\title{
Screening for gestational diabetes: evaluation of prevalence in age- stratified subgroups at Central hospital Warri Nigeria
}

\author{
Orru M. I. ${ }^{1}$, Nwose E. U. ${ }^{1,2 *}$, Bwititi P. T. ${ }^{3}$, Igumbor E. O. ${ }^{1}$
}

\begin{abstract}
${ }^{1}$ Department of Public and Community Health, Novena University Ogume, Nigeria
${ }^{2}$ Department of Community Health, Charles Sturt University, New South Wales, Australia

${ }^{3}$ Department of Biomedical Sciences, Charles Sturt University, New South Wales, Australia
\end{abstract}

Received: 09 November 2017

Accepted: 22 November 2017

\section{*Correspondence:}

Dr. Nwose E. U.,

E-mail: enwose@csu.edu.au

Copyright: (C) the author(s), publisher and licensee Medip Academy. This is an open-access article distributed under the terms of the Creative Commons Attribution Non-Commercial License, which permits unrestricted non-commercial use, distribution, and reproduction in any medium, provided the original work is properly cited.

\section{ABSTRACT}

Background: The prevalence of gestational diabetes depends on the method of diagnosis as well as ethnic background. Maternal age has also been identified as a factor, but has not been given much attention. The notion of gestational prediabetes has also speculated, but is equally yet to be a focus in discussion. This work aimed at evaluating the screening for gestational diabetes in Central Hospital, Warri; to determine prevalence of gestational diabetes in the general population and in stratified age groups. The other objective was to investigate the effectiveness and use of the methods of diagnosis.

Methods: This was a retrospective review of laboratory data of de-identified antenatal patients. Hospital records of gestational diabetes from 2013 to 2015 were obtained from the Central Hospital, Warri. Data collected included age of the de-identified patients, blood glucose results and whether the test was fasting or random. Other information was the month/year of test. A total of 3589 results were analyzed.

Results: Averaged prevalence of $5.85 \%$ is identified. Fasting blood sugar (FBS) measurement was used more and it also identified more positives $(9 \%)$ compared to random blood sugar $(<2 \%)$. On a dichotomous age group, prevalence of gestational diabetes appeared low in women below 25 years compared to those $\geq 26$ years old. In a more stratification of age groups, potential antepartum prediabetes in pregnancy was lower in women above 40 years old relative to the younger age subpopulations $(\mathrm{p}<0.000001)$. No significant variation was observed in level of usage of either method between months/years.

Conclusions: There is an ongoing good practice of using affordable screening test, which is FBS. The significant finding was that there may be up to $9 \%$ prevalence of GDM and that this number may erroneously be lower if random blood glucose measurement is used. Another worthy observation was that the prevalence in stratified age groups was non-directional, especially as potential prediabetes is higher in the younger age subpopulation.

Keywords: Gestational prediabetes, Maternal age, Prevalence, Screening methods, Women

\section{INTRODUCTION}

In terms of prevalence of gestational diabetes: there is a suggestion that global prevalence of gestational diabetes mellitus (GDM) is about $7 \%$ and according to the American Diabetes Association (ADA), prevalence may range from 1 to $14 \% .{ }^{1}$ However, reports from some parts of Nigeria indicates a strikingly low prevalence of approximately $0.7 \% .^{2}$ According to the International Diabetes Federation, the following estimations constitutes the facts that make the theme for World Diabetes Day of $2017 .^{3}$

- $10 \%$ of women are living with diabetes 
- $40 \%$ of female diabetes patients are of reproductive age

- $50 \%$ of women with GDM history progress to develop type 2 diabetes

- $50 \%$ of patients with hyperglycaemia in pregnancy are under 30 years old

- $14 \%$ births are affected by gestational diabetes

- $16 \%$ of births to women in 2015 were associated with hyperglycaemia in pregnancy.

It is generally agreed that prevalence may depend of diagnostic criteria vis-à-vis method employed. Reports from India, Kenya and United States suggest prevalences of about $7 \%, 3 \%$ and $6 \%$, respectively. ${ }^{4-6} \mathrm{~A}$ study from China that was based on 1999 WHO criteria indicated approximately $8 \%$, but the level increased to $9.3 \%$ when the International Association of Diabetes and Pregnancy Study Group (IADPSG) criteria was applied. ${ }^{7}$ Another report from Australia indicated 9\% based on Australasian Diabetes in Pregnancy Society (ADIPS) criteria and 13\% using the IADPSG. ${ }^{8}$ It is of particular interest that these prevalence reports are higher than what is being reported from Nigeria. Meanwhile, such study has yet to be conducted in Delta state of Nigeria, at least, in recent times.

On screening methods for GDM: there are several criteria or methods for GDM screening and the array of recommendations for screening of GDM will continue to evolve, especially as convenience and affordances are factors. For instance, while the one-step 75g OGTT and the two-steps '50g OGT followed by 100g OGTT', as well as fasting blood sugar (FBS) and random blood sugar (RBS) methods remain, HbA1c method is still advocated. ${ }^{9-14}$ There are also the ADIPS recommendations, and National Institute of Health and Clinical Excellence (NICE) screening criteria. ${ }^{8}, 15$ While the method used by any health facility may be a factor of logistics, there is obviously confusion and there are implications for management of patients diagnosed. ${ }^{16-18} \mathrm{It}$ may be interesting to verify if this confusion reflects in a significant variation in the method employed in GDM between periods of e.g. comparing months in different years.

Perhaps, a point to consider as part of screening is the practice of selective screening. ${ }^{19,20}$ In resource-deficient low-mid income countries such as Nigeria, this is a common practice. In some instances, the selection is based on patient's ability to pay for the screening test. Whether this practice improves the level of patients identified with GDM is of interest to investigate.

Regarding maternal age versus GDM: there are suggestions that age of antenatal patients has a role to play in development of GDM. ${ }^{6,21}$ On this basis, there is a 25 years cut-off speculated as recommendation of minimum age for antenatal patients to qualify for GDM screening, but it is acknowledged that research evidence is lacking to support this recommendation. ${ }^{21}$ However, a critical review of available two literatures on prevalence of GDM in stratified age-groups do suggest unidirectional increase with age (Figure 1).

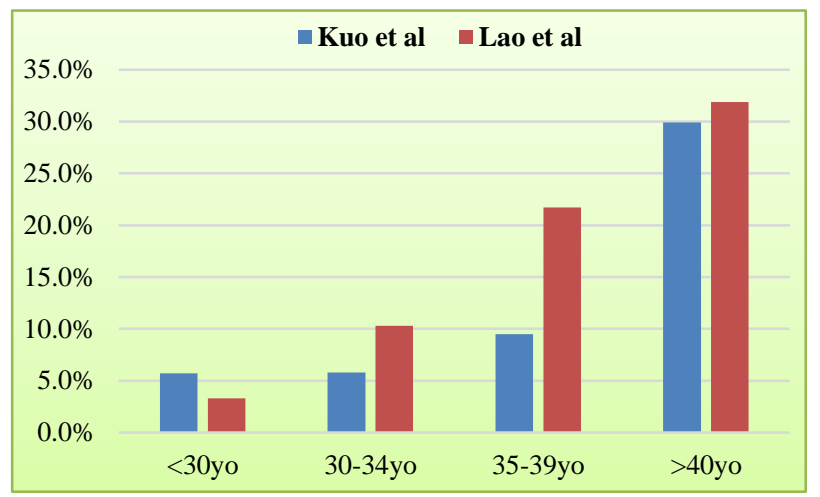

Figure 1: Prevalence of GDM indicating disparity but unidirectional change.

Given the foregoing, it may benefit the low-mid income communities to ascertain the cost effectiveness of universal screening compared to selectively excluding patients who are below 25 years old. Thus, the objective of the work is to perform a retrospective review of data to determine the prevalence of gestational diabetes at Warri Central hospital including how it varies in age groups, as well as whether the methods screening vary from year to year.

\section{METHODS}

This study was approved by the relevant research ethics authorities of Novena University and Warri Central hospital. The study was purposed to be retrospective review of archived data. Support of the medical records department was solicited to mine de-identified data. The main information requested were age of the de-identified patient, result of blood sugar test, type of blood sugar test (whether FBS or RBS), and month/year of the test. A total of 3589 results were mined in the period 2013 2015. Specifically, data were from September and October 2013, May to November 2014, and June to December 2015. Based on data available, all the test results for the months of September and October in the consecutive three years' data were selected for comparison.

In this study, blood sugar results were considered positive on the basis of FBS $\geq 100 \mathrm{mg} / \mathrm{dL}$, or RBS $\geq 200 \mathrm{mg} / \mathrm{dL}$. The positives were discretionally classified into either diabetes (FBS $\geq 126 \mathrm{mg} / \mathrm{dL}$, or $\mathrm{RBS} \geq 200 \mathrm{mg} / \mathrm{dL}$ ) or prediabetes (FBS: $101-125 \mathrm{mg} / \mathrm{dL}$, or RBS: $140-199$ $\mathrm{mg} / \mathrm{dL}$ ). The assessment of prediabetes is in view of the World Diabetes Day 2017, which highlights that prevalence of hyperglycaemia in pregnancy, and will be expatiated in another short communication. ${ }^{3}$

Data were variously sorted for four different statistical analyses. First, data were sorted on the basis of test 
methods (i.e. FBS vs. RBS) and analyzed for comparative percentage of the positive results identified by either method - to determine level of effectiveness. Secondly, data were resorted and categorized into dichotomous age groups of ' $\leq 25$ years old' vs. ' $\geq 26$ years old'. Analysis was performed to determine prevalence of positive results in the age groups and compared FBS vs. RBS. A third analysis was a repeat of the second, but with the data stratified into four groups for FBS and five groups for RBS (Table 1). Lastly in the fourth analysis, data were sorted by month/year of test and those from two consecutive months (September and October) in the three consecutive years were selected. The percentage levels of FBS as well as positives were compared to determine any variation between months or years.

Table 1: Definition and sample size of stratified agegroups.

\begin{tabular}{|c|c|c|}
\hline Group & Definition & $\mathbf{N}$ \\
\hline G1 & $<30$ yо FBS & 456 \\
\hline $\mathrm{G} 2$ & 30 - 34yо FBS & 499 \\
\hline G3 & 35 - 39yо FBS & 481 \\
\hline G4 & $\geq 40$ yо FBS & 633 \\
\hline G5 & $<30$ yо RBS & 394 \\
\hline G6 & 30 - 34yo RBS & 109 \\
\hline G7 & 35 - 39yо RBS & 294 \\
\hline G8 & 40yo RBS & 642 \\
\hline G9 & $>40$ yo RBS & 351 \\
\hline Total & & $385^{\circ}$ \\
\hline
\end{tabular}

\section{RESULTS}

The results show that FBS method was employed more than the RBS and there were 2069 FBS, out of which 366 were hyperglycaemic. RBS method comprised 1790 , including 54 hyperglycaemic results (Table 2). Therefore, FBS identifies much more positives than the RBS method (Figure 2).

Table 2: Descriptive statistics of FBS vs. RBS test results.

\begin{tabular}{|lll|}
\hline & FBS & RBS \\
\hline Mean age (years) & 34.69 & 36.06 \\
\hline Mean & 90.75 & 90.10 \\
\hline Median & 78 & 88 \\
\hline Mode & 76 & 84 \\
\hline Standard Deviation & 34.74 & 18.44 \\
\hline Kurtosis & 12.52 & 84.93 \\
\hline Skewness & 3.21 & 6.23 \\
\hline Range & 261 & 404 \\
\hline Minimum & 37 & 37 \\
\hline Maximum & 298 & 441 \\
\hline Count & 2069 & 1790 \\
\hline Diabetes level & 196 & 14 \\
\hline Prediabetes level & 170 & 40 \\
\hline
\end{tabular}

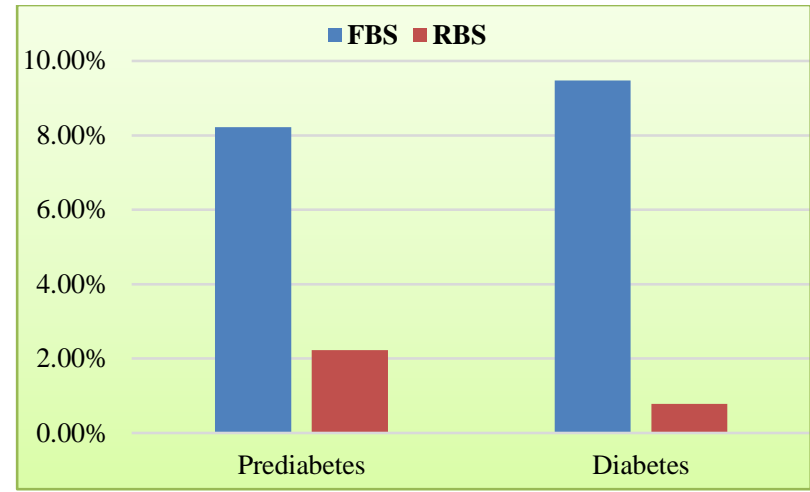

Figure 2: Percentage prevalence of GDM and preGDM based on FBS vs. RBS.

The results of analyses of prevalence in age groups show a normal average level of blood glucose in all groups (Tables 3 and 4).

Table 3. Descriptive statistics of blood sugar results in dichotomous age-groups.

\begin{tabular}{|lllll|}
\hline FBS & year & $\begin{array}{l}\mathbf{2 5} \\
\text { year RBS }\end{array}$ & $\begin{array}{l}\geq 26 \\
\text { year FBS }\end{array}$ & $\begin{array}{l}\geq 26 \\
\text { year } \\
\text { RBS }\end{array}$ \\
\hline Mean & 75.54 & 89.92 & 91.85 & 90.13 \\
\hline $\begin{array}{l}\text { Median } \\
\text { Mode }\end{array}$ & 73 & 91 & 79 & 88 \\
\hline $\begin{array}{l}\text { Standard } \\
\text { deviation }\end{array}$ & 10.95 & 11.96 & 35.61 & 19.29 \\
\hline $\begin{array}{l}\text { Sample } \\
\text { variance }\end{array}$ & 119.96 & 142.94 & 1267.98 & 372.00 \\
\hline Kurtosis & 27.56 & 30.99 & 11.69 & 81.57 \\
\hline Skewness & 4.68 & 2.57 & 3.11 & 6.22 \\
\hline Range & 93 & 163 & 261 & 399 \\
\hline Minimum & 62 & 37 & 37 & 42 \\
\hline Maximum & 155 & 200 & 298 & 441 \\
\hline Count & 140 & 249 & 1929 & 1541 \\
\hline
\end{tabular}

However, by the FBS method, prevalence of positives is lower in ' $\leq 25$ years old' group relative to the older group (Figure 3).

The prevalence changed in the stratified age groups to show non-directional increase in prevalence of GDM. For instance, level of GDM as indicated by FBS is higher is 30-34 years group compared to 35-39 years; and prediabetes identified by both FBS and RBS is least in the oldest age-group especially relative to preceding two age stratifications (Figure 4; $\mathrm{p}<0.000001$ ).

On the objective to evaluate if there are differences in methods and results between months or years, two consecutive months (September and October) were discretionally selected from the limited data. Total number of tests and positive results for the two months were collated (Table 4). 
Table 4: Descriptive statistics of stratified age-groups.

\begin{tabular}{|lllllllllll|}
\hline & G1 & G2 & G3 & G4 & G5 & G6 & G7 & G8 & G9 \\
\hline Mean & 76 & 87 & 87 & 107 & 88 & 86 & 98 & 88 & 89 & 96 \\
\hline Median & 74 & 78 & 89 & 87 & 88.5 & 79 & 94 & 86 & 90 \\
\hline Mode & 64 & 67 & 91 & 76 & 86 & 73 & 94 & 84 & 90 \\
\hline Standard Deviation & 12 & 27 & 13 & 52 & 12 & 32 & 26 & 17 & 9 \\
\hline Kurtosis & 8 & 4 & 27 & 4 & 25 & 1 & 102 & 35 & 12 \\
\hline Skewness & 2 & 2 & 3 & 2 & 3 & 1 & 8 & 6 & 1 \\
\hline Range & 93 & 168 & 154 & 261 & 163 & 115 & 384 & 174 & 92 \\
\hline Minimum & 62 & 52 & 66 & 37 & 37 & 42 & 57 & 59 & 59 \\
\hline Maximum & 155 & 220 & 220 & 298 & 200 & 157 & 441 & 233 & 151 \\
\hline Count & 456 & 499 & 481 & 633 & 394 & 109 & 294 & 642 & 351 \\
\hline
\end{tabular}

ANOVA comparison of groups $1-4$ on one hand and groups $5-9$ on another showed statistical significance $(\mathrm{p}<0.000001)$.

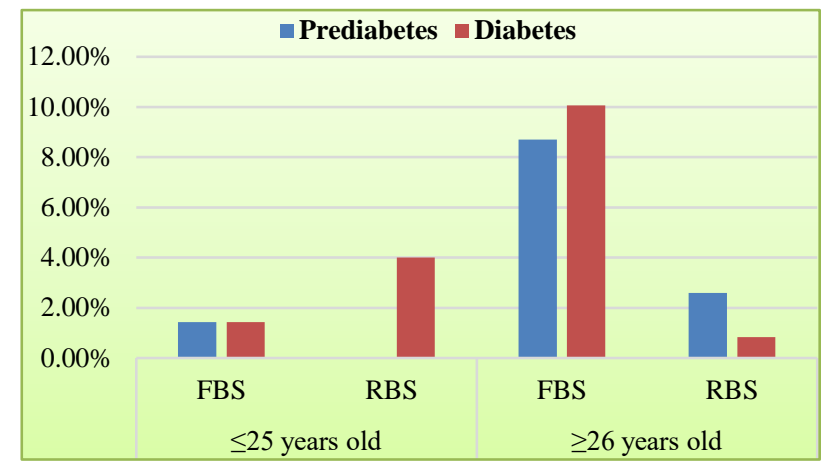

Figure 3: Percentage prevalence of GDM and preGDM in stratified age-groups.

Given the unequal numbers; the fractions of tests and positive results in each month from the two months' totals were determined as percentages for comparison. The results show that there were more tests and more positive results in October compared to September in a year and vice versa in the other two years with no overall statistical significant difference (Figure 4, p >0.05).

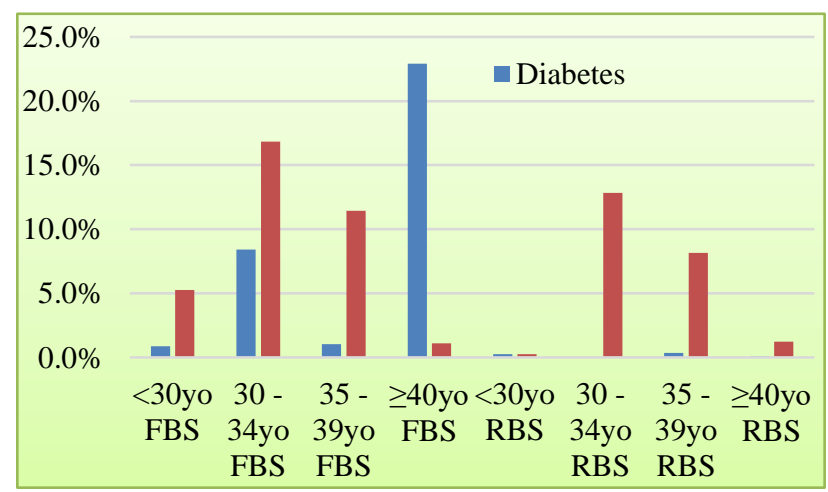

Figure 4: Prevalence of GDM and probable prediabetes in stratified age groups.

Further results show no difference in the level of FBS or RBS used as screening method when each month is viewed as a fraction of the entire two months of the year
(Figure 5), although September of 2014 was notably $100 \%$ FBS method (Figure 6).

Table 5: Number of tests and positive results in the same 2 months of 3 years.

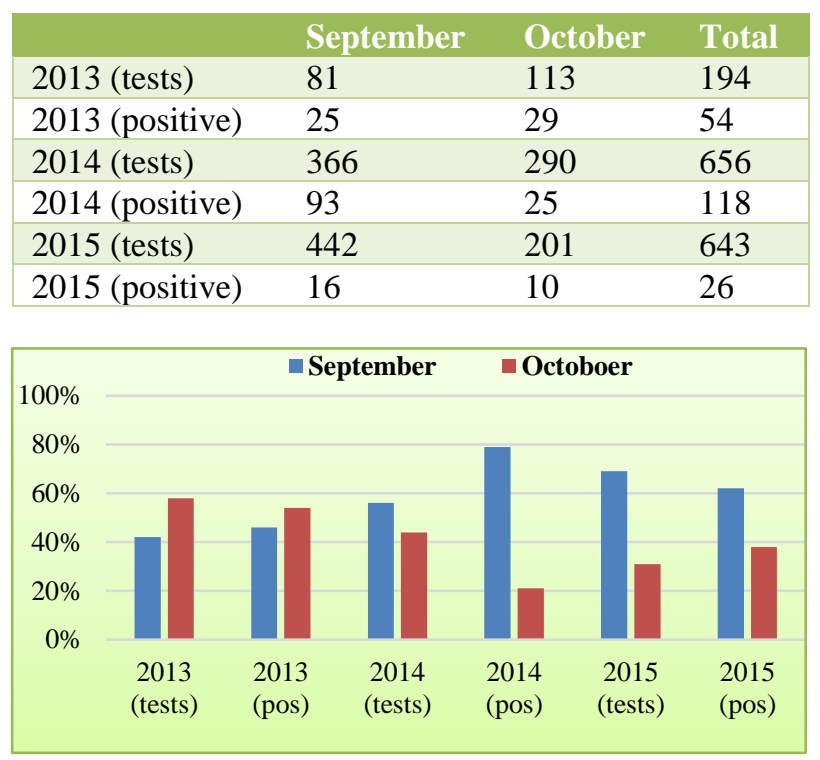

Figure 5: Comparative \% of tests and positive results in the same 2 months of 3years.

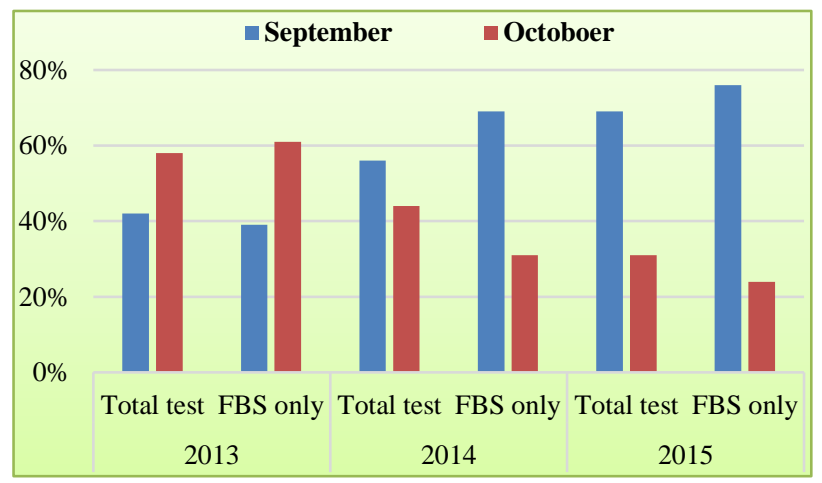

Figure 6: Comparative \% of tests and FBS methods in the same 2 months of 3 years. 


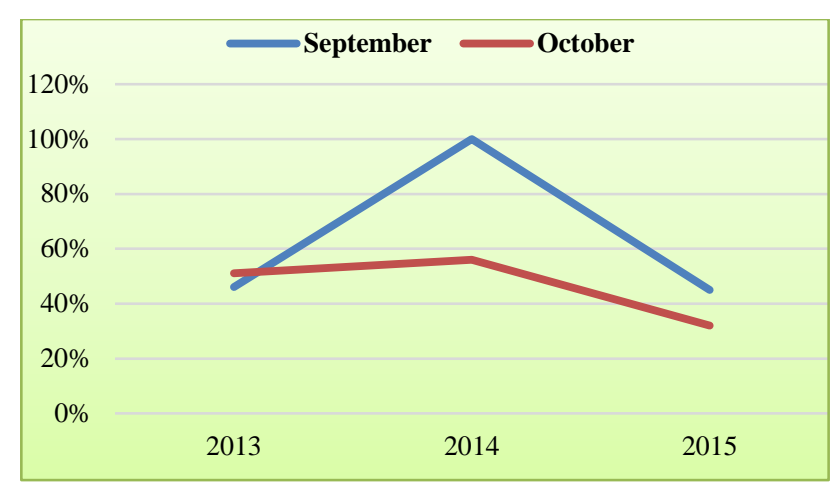

Figure 7: Comparative \% of FBS method within each month in the 3 years.

\section{DISCUSSION}

P On the prevalence of GDM in stratified age groups, results from this retrospective analysis show greater than 9\% prevalence of GDM identified by FBS method relative to less than $1 \%$ from RBS method (Figure 1). Significantly, a lower prevalence in women bellow 25years old compared to the dichotomous group constituting those who are 26 years or older is observed (Figure 2). The current notion or suggestion is that is that GDM screening should be limited to women who are above 25 years. ${ }^{21}$ Therefore, it may be taken that this observation justifies the need to exclude antenatal patients who are below 25 years from GDM screening unless there is a history of diabetes or CVDs in the family or the are symptoms of BM.

However, results show non-directional increase in prevalence of GDM in the more stratified age groups. For instance, level of GDM as indicated by FBS was higher in 30-34 yaers group compared to 35-39 years; and prediabetes identified by both FBS and RBS was least in the oldest age-group especially relative to preceding two age stratifications (Figure 3). The two literatures that were critically reviewed had indicated disparity prevalence of GDM but unidirectional change. ${ }^{21,22}$ Therefore, this report provides another contrary evidence for consideration.

Another observation worth noting is the potential prevalence of prediabetes among the pregnant women population reviewed (Figures 1-3). The notion of gestational prediabetes has been suggest since about 7 years ago. ${ }^{23}$ Therefore, this is a pertinent finding that will be expatiated in another short communication, especially as part of the theme for World Diabetes Day of 2017. ${ }^{3}$

In GDM screening, OGTT may be a gold standard but least convenient, while FBS is considered better than RBS. Results from this retrospective study shows that FBS method in GDM screening yields the expected superiority in identification of patients (Figure 1 and 2). Thus, this report indicates good practice regarding method of GDM screening at Warri Central hospital.
However, there is dearth of data in the literature regarding frequency or level of usage of either FBS or RBS - i.e. to advice any need for commendation or review of practice. Although, statistical significance is neither achieved in incidence of GDM (Figure 4), nor level of use of methods (Figure 5), the graphical results show that FBS was used more than RBS. For instance, only FBS was used in the entire month of September 2014 (Figure 6). In clinical practice, it is common to monitor events periodically - e.g. hourly, daily, weekly, monthly or yearly. Therefore, the significance of this observation is contribution of evidence base that there is still room for improvement in the choice of FBS over RBS as a screening method for GDM.

Recently, a report from Port Harcourt, Nigeria indicated a prevalence of $0.7 \%$, which is an increase from the previously reported $0.3 \%$ in 2001 in the same population. ${ }^{2,24}$ In a different population, the reported prevalence was approximately $1 \% .{ }^{25}$ In this retrospective study of antenatal patient population who were selectively screened for GDM, FBS test method identified as much as $9 \%$ prevalence, excluding another $8 \%$ that could be termed gestational prediabetes. Indeed, it is estimated that prevalence of GDM ranges from 1 to $14 \%$, or average of $7 \%$, depending on method of testing and population. ${ }^{1}$ Thus, the observation of $9 \%$ prevalence reported here is more in line with global estimate.

\section{CONCLUSION}

This study has purposed to investigate the prevalence of gestational diabetes at Warri Central hospital including how it varies in age groups, as well as whether the method screening vary from year to year. The results show that FBS identifies up to 9\% prevalence of GDM and that this number may erroneously be lower if RBS method is used. Secondly, variation of prevalence in stratified age groups is non-directional as the least diabetic and prediabetic levels were observed over 40 years old of this study subpopulation. Thirdly, the nonstatistically significant more usage of FBS relative to RBS methods connotes an ongoing good practice with room for improvement.

\section{ACKNOWLEDGMENTS}

The public health dissertation committee of Novena University has made valuable contribution in focusing of this research and is hereby acknowledge. The medical records department and ethical committee as well as laboratory staff of the Warri Central hospital were instrumental in data mining and logistics of this project and are also hereby appreciated.

Funding: No funding sources

Conflict of interest: None declared 
Ethical approval: The study was approved by the Institutional Ethics Committee

\section{REFERENCES}

1. American Diabetes Association. Gestational diabetes mellitus. Diabetes Care. 2003;26(suppl 1):s103-s5.

2. John CO, Alegbeleye JO, Otoide AO. Foetomaternal outcome of diabetes in a tertiary health facility in Nigeria. Afr J Diabet Med. 2015;23(3):136.

3. International Diabetes Federation. World Diabetes Day 2017: 2017 [2 $2^{\text {nd }}$ Novembeer, 2017]. Available at https://www.idf.org/our-activities/world-diabetesday/wdd-2017.html.

4. Pastakia SD, Njuguna B, Onyango BA, Washington S, Christoffersen-Deb A, Kosgei WK, et al. Prevalence of gestational diabetes mellitus based on various screening strategies in western Kenya: a prospective comparison of point of care diagnostic methods. BMC Pregnancy Childbirth. 2017;17(1):226.

5. Garrison A. Screening, diagnosis, and management of gestational diabetes mellitus. Am Fam Physician. 2015;91(7):460-7.

6. Rajput R, Yadav Y, Nanda S, Rajput M. Prevalence of gestational diabetes mellitus and associated risk factors at a tertiary care hospital in Haryana. Indian J Med Res. 2013;137(4):728-33.

7. Leng J, Shao P, Zhang C, Tian H, Zhang F, Zhang S, et al. Prevalence of gestational diabetes mellitus and its risk factors in Chinese pregnant women: a prospective population-based study in Tianjin, China. PLoS One. 2015;10(3):e0121029.

8. Moses RG, Morris GJ, Petocz P, San Gil F, Garg D. The impact of potential new diagnostic criteria on the prevalence of gestational diabetes mellitus in Australia. Med J Aust. 2011;194(7):338-40.

9. Lieberman N, Kalter-Leibovici O, Hod M. Global adaptation of IADPSG recommendations: a national approach. Int J Gynaecol Obstet. 2011;115(Suppl 1):S45-7.

10. Virally M, Laloi-Michelin M. Methods for the screening and diagnosis of gestational diabetes mellitus between 24 and 28 weeks of pregnancy. Diabetes Metab. 2010;36(6 Pt 2):549-65.

11. Committee on Practice Bulletins-Obstetrics. Practice Bulletin No. 180: Gestational Diabetes Mellitus. Obstet Gynecol. 2017;130(1):e17-e37.

12. Odsæter IH, Åsberg A, Vanky E, Mørkved S, Stafne $\mathrm{SN}$, Salvesen KA, et al. Hemoglobin A1c as screening for gestational diabetes mellitus in Nordic Caucasian women. Diabetol Metab Syndr. 2016;8(1):43.

13. Khalafallah A, Phuah E, Al-Barazan AM, Nikakis I, Radford A, Clarkson W, et al. Glycosylated haemoglobin for screening and diagnosis of gestational diabetes mellitus. BMJ Open. 2016;6(4):e011059.

14. Aldasouqi SA, Solomon DJ, Bokhari SA, Khan PM, Muneera S, Gossain VV. Glycohemoglobin A1c: A promising screening tool in gestational diabetes mellitus. Int J Diabetes Dev Ctries. 2008;28(4):1214.

15. Sukumaran S, Madhuvrata $\mathrm{P}$, Bustani R, Song S, Farrell TA. Screening, diagnosis and management of gestational diabetes mellitus: A national survey. Obstetr Med. 2014;7(3):111-5.

16. Agarwal MM, Shah SM, Al Kaabi J, Saquib S, Othman Y. Gestational diabetes mellitus: Confusion among medical doctors caused by multiple international criteria. J Obstet Gynecol Res. 2015;41(6):861-9.

17. Rani PR, Begum J. Screening and Diagnosis of Gestational Diabetes Mellitus, Where Do We Stand. Journal of clinical and diagnostic research. JCDR. 2016;10(4):QE01-QE4.

18. Benhalima K, Van Crombrugge $\mathrm{P}$, Verhaeghe J, Vandeginste S, Verlaenen H, Vercammen C, et al. The Belgian Diabetes in Pregnancy Study (BEDIP$\mathrm{N}$ ), a multi-centric prospective cohort study on screening for diabetes in pregnancy and gestational diabetes: methodology and design. BMC Pregnancy Childbirth. 2014;14:226.

19. Berger H, Sermer M. Counterpoint: Selective Screening for Gestational Diabetes Mellitus. Diabetes Care. 2009;32(7):1352-4.

20. Alberico S, Strazzanti C, De Santo D, De Seta F, Lenardon $\mathrm{P}$, Bernardon $\mathrm{M}$, et al. Gestational diabetes: universal or selective screening? J Maternal-Fetal Neonat Med. 2004;16(6):331-7.

21. Lao TT, Ho LF, Chan BCP, Leung WC. Maternal age and prevalence of gestational diabetes mellitus. Diabetes Care. 2006;29(4):948-9.

22. Kuo CH, Chen SC, Fang CT, Nien FJ, Wu ET, Lin SY, et al. Screening gestational diabetes mellitus: The role of maternal age. Plos One. 2017;12(3):e0173049.

23. Ray JG, Berger H, Lipscombe LL, Sermer M. Gestational prediabetes: a new term for early prevention? Indian J Med Res. 2010;132:251-5.

24. Wokoma FS, John CT, Enyindah CE. Gestational diabetes mellitus in a Nigerian antenatal population. Trop J Obstet Gynecol. 2001;18(2):56060.

25. Ozumba BC, Obi SN, Oli JM. Diabetes mellitus in pregnancy in an African population. Int $\mathbf{J}$ Gynaecol Obstet. 2004;84(2):114-9.

Cite this article as: Orru MI, Nwose EU, Bwititi PT, Igumbor EO. Screening for gestational diabetes: evaluation of prevalence in age-stratified subgroups at Central hospital Warri Nigeria. Int J Reprod Contracept Obstet Gynecol 2018;7:68-73. 